\title{
An Android Application for Farmers to Disseminate Horticulture Information
}

\author{
Vimal B. Patel \\ Assistant Professor \\ College OF Agriculture, \\ Navsari Agriculture University, \\ Waghai, India, 394730
}

\author{
Rahul G. Thakkar \\ Assistant Professor \\ College Of Agri-Busniess \\ Management, Navsari \\ Agriculture University, Navsari, \\ India, 396450
}

\author{
Bankim L.Radadiya, Ph.D \\ Associate Professor \\ College Of Agri-Busniess \\ Management, Navsari \\ Agriculture University, Navsari, \\ India, 396450
}

\begin{abstract}
Today's the mobile phone is used worldwide. As the price of smart phone is decreasing, its popularity is increasing day by day. Moreover, android is the mobile operating system used in smart phone, most of its applications are freely available. The use of smart phone is increase in every sector of business, education, etc. So in this research paper, using the concept of Horticulture and Android introduces a "Farmer Helping Service" system that will provide the detail information of fruits, vegetables and flowers in audio format to the farmers. This system can provide information using android smart phone from anywhere and anytime without using internet and at free of cost. It is very useful to Gujarat Farmer because they will get information in Gujarati Language just by typing number from the mobile keypad. An illiterate person can also easily operate the system.
\end{abstract}

\section{Keywords}

Android, Horticulture, Gujarati Language, Farmer, Fruit, Smart phone

\section{INTRODUCTION}

In recent days, Android Smart Phone is becoming more popular due to low price and free applications. Smart phone makes all our tasks fast, efficient $\&$ accurate. Android Market allows Android Smart Phone users to download application freely. Due to this android features, in our research paper we have combined the concept of Horticulture and Agriculture sector to utilize the maximum benefit of android technology.

Horticulture is a one type of arts which is useful in cultivation of fruits, flowers, vegetables or ornamentals plants. Horticulture contains study of fruits, vegetables, flowers etc.

Android is an Operating System for mobile device and also a platform to developed key application for the Smart Phone..Java Programming Language is used to developed Android Application by using Android SDK tools and API.

Android Architecture: Android provides an open source development platform that offers developers the strength to build extremely powerful applications. Android help Developers to take free advantage of the device hardware, access location information, run background services, divert call and messages, etc.

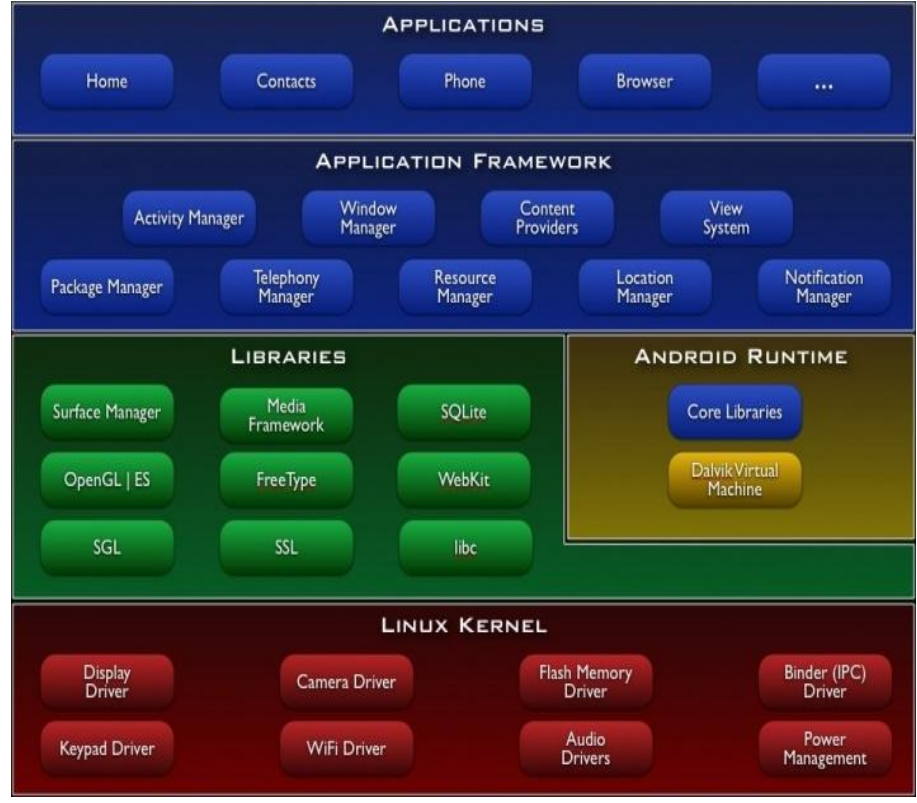

Fig. 1 Android Framework

For developing key application developers take the advantages of same framework APIs. Application architecture use reusability features of components. Once the application has been published, its capabilities are reuse by other applications. Thus it allows the one component to replace by others components. Below listed all applications are a set of services and systems use in developing this application, including:

- To build an application consists of buttons and textboxes used rich set of Views..

- The lifecycle of application and navigation back stack is manages by an Activity Manager.

- Used of telephony services on the device to access information is provides by Telephony Manager.

- To Control the volume and ringer mode is managed by an Audio Manager

- To receive intents send by other application into our own application can by managed by Broadcast method of Broadcast Receiver service. Using this method events raised by any application can be handle by our application. [11]

Now in our system, we take the horticulture information for flowers, vegetables and fruits like soil required for their 
plantation, season in which they grows, which types of fertilizer and how much quantity required to them, which are their different categories and other much more information that are mostly required by the farmer to harvest them. After that all horticulture information is converted into voice data in our system and whenever farmer required that information, they just used the system and retrieved it just used the keypad of their android phone.

\section{OBJECTIVES}

\subsection{Primary Objective}

The main objective to introduce this system is to provide the flowers, fruits and vegetables details information(such as soil ,fertilizer, method for harvesting, etc) to the farmer in voice form, free of cost, anytime, anywhere using Android smart phone without Internet Service. All voice data is in Gujarati Language so, the illiterate farmers of Gujarat can easy operate the system and retrieved data from it.

\subsection{Secondary Objective}

- The general purpose of designing the system is to develop a mobile based application that can be used by any user.

- $\quad$ System is so user friendly that a farmer just has to type number from the mobile keypad and desired information is available on the screen.

- $\quad$ System once install in Android smart phone, it provide information $24 \mathrm{X} 7$ and it free from network coverage problem also.

- $\quad$ System is freely available on Android market and once it is downloaded and install in Smart phone it provides information without internet service.

\section{PROBLEM STATEMENT}

After completing the intensive study of data following problem are identified:-

- Various website provides Horticulture information related to fruit, flowers and vegetables. But all the information is in English Language and in Text form. So illiterate farmers of Gujarat are not able to take advantage of these services.

- If some literate farmer want to access website, but then a laptop or personal computer is mandatory.

- Using mobile phone, some farmer can access website, but then also constant internet services is required.

- There are some agency like IFFCO Kisan Sanchar Limited (IKSL) [] and Reuters Marker Light (RML) that provide agriculture information via SMS or call. But they charge money for the usage of their services and also don't work where mobile tower is not available.

\section{METHODOLOGY}

To overcome the limitations mention in problem statement. We have design a system that will provide the horticulture information to the farmer using Android phone in form of voice data. No cost of pc \& laptop is required. No internet services required. All the information is provided in Gujarati
Language so the literate farmers of Gujarat State can easily operate the system just by dialing numbers from the mobile keypad. No call or SMS charges, it provides free information anywhere and anytime. As the system gets installed on Android phone, tower problem will not be a problem anymore.

\subsection{System Design \& Implementation Architecture}

Below Figure show the System Design Architecture flow chart that will take number as input from the mobile keypad and give horticulture information in voice form to the farmers.

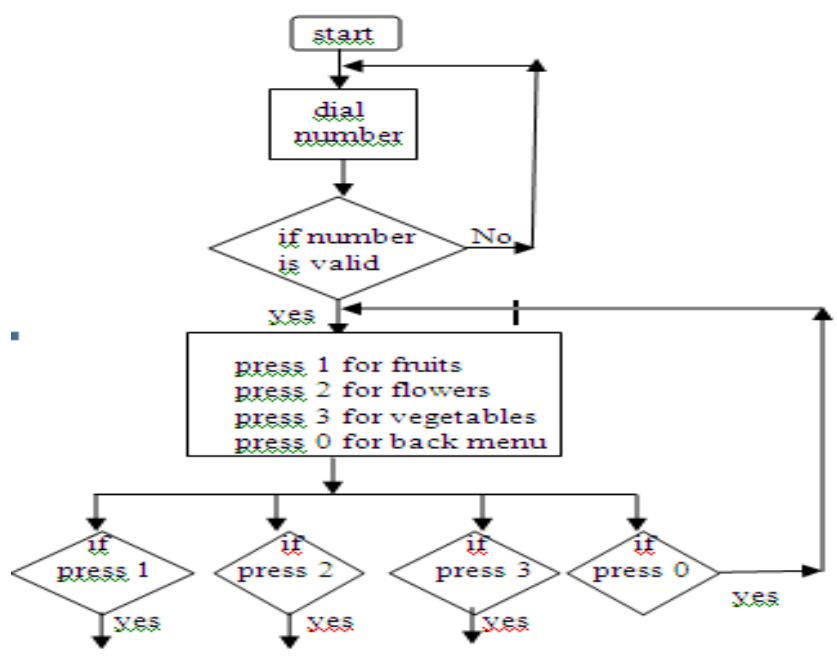

Figure - 2: Flow Chart for Proposed System

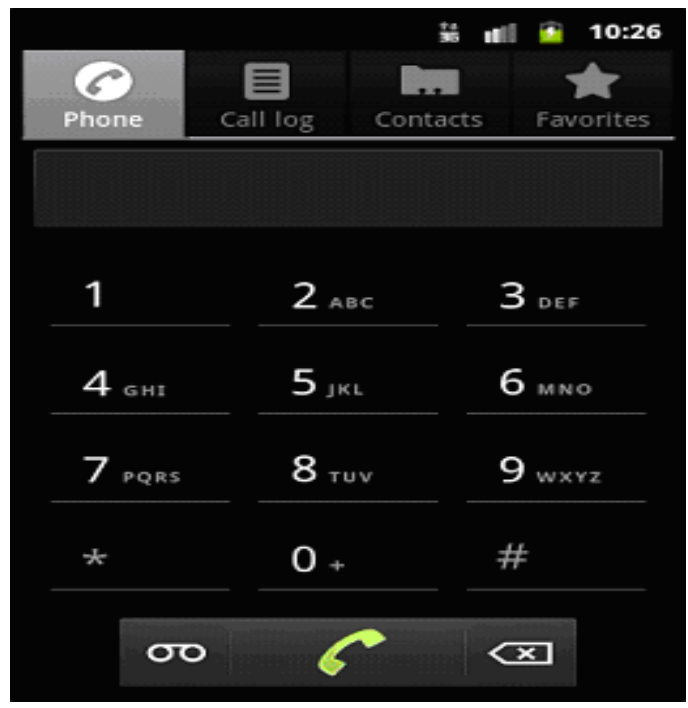

Fig. 3 Starting stage of Application

We assume that farmer has press 1 as an input, then further system will check input value and provide information base upon the input provided( system provide information about fruits). And further allow user to select information from fruits category. Example press 1 for tropical zone fruit, press 2 for subtropical zone fruit, press 3 for temperate zone fruit and 0 to return to back menu. 


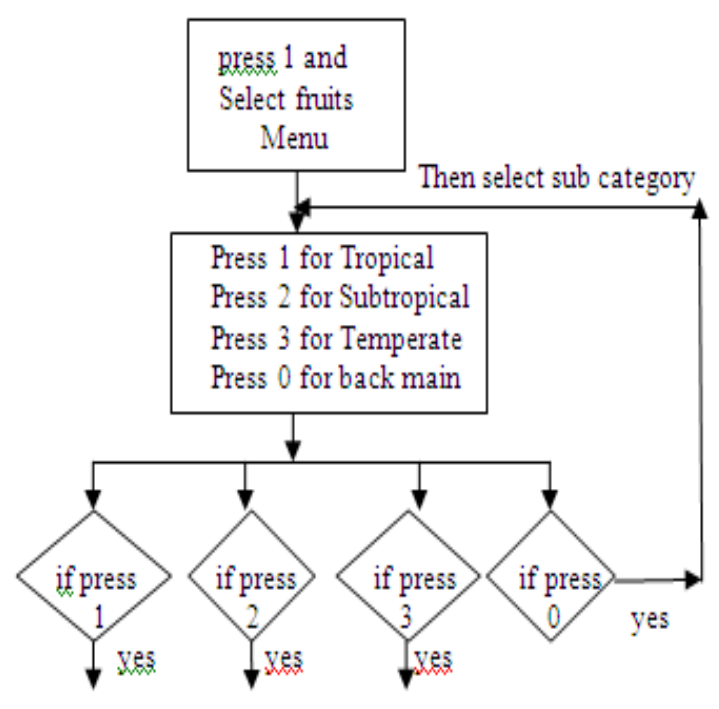

Fig. 4 Selection of Fruit Subcategory

Again we assume that farmer has press 2 then system will input value again and base on that input value provide further information. Examples press 1 for jamrukh (guava), press 2 for dadham (pomegranate), press 3 for (drasha) Grapes and 0 to return to back menu.

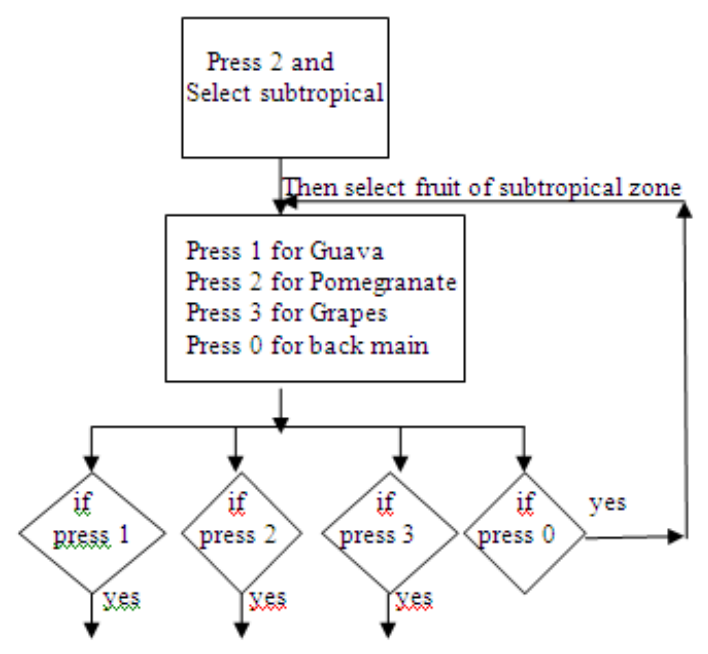

Fig. 5 Selection of Fruit Category

Now if farmer has press 1 then system provides fully information about jamrukh (guava). Information includes type of soil required for plantation, season information, which type of fertilizer for best growth, etc.

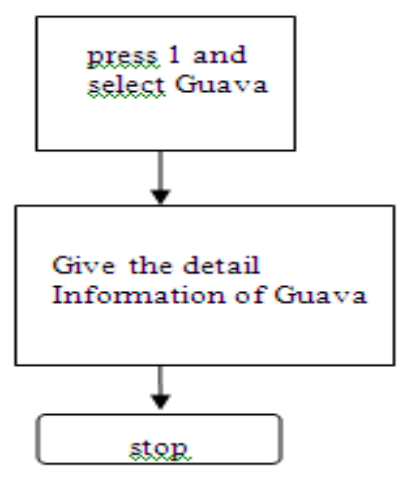

Fig. 6 Selection of Fruit

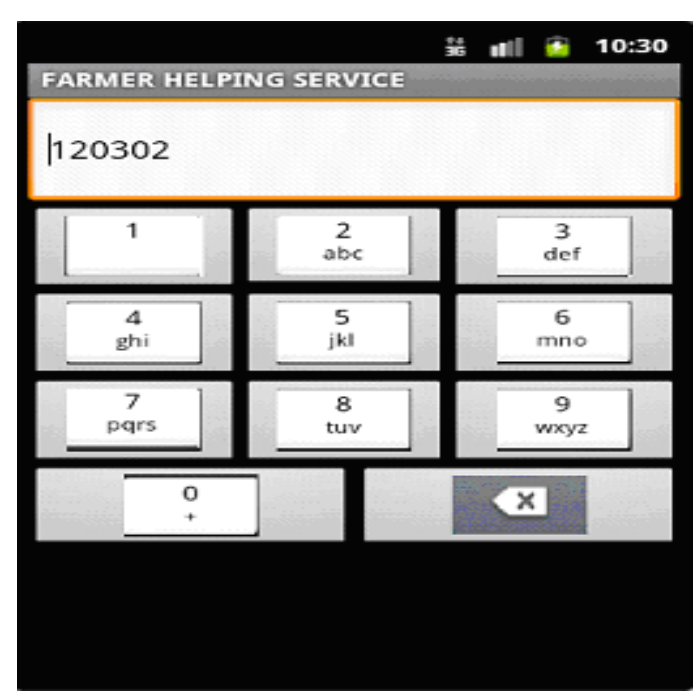

Fig. 7 Details of Fruit Information

Above whole process is repeated for flowers and vegetables also.

\section{CONCLUSION}

From the above study it is conclude that the "Farmer Helping Services" system provide all the Horticulture information related to fruits, flowers and vegetables in Gujarati Language to the illiterate farmers in voice form without used of internet. No cost is required for this system and also it provides information $24 * 7$ from any location.

\section{REFERENCES}

[1] Mittal, Surabhi, and Gaurav Tripathi. "Role of Mobile Phone Technology in Improving Small Farm Productivity1." Economic Survey (2008): 09.

[2] Lakhtaria, K. I. (2009, December). Enhancing QOS and QOE in IMS enabled next generation networks. In Networks and Communications, 2009. NETCOM'09. First International Conference on (pp. 184-189). IEEE.

[3] Das, Ashutosh, Debabrata Basu, and Rupak Goswami. "Accessing Agricultural Information through Mobile Phone: Lessons of IKSL Services in West Bengal." 2012

[4] Lakhtaria, Kamaljit I., and Dhinaharan Nagamalai. "Analyzing Web 2.0 Integration with Next Generation Networks for Services Rendering." Recent Trends in 
Networks and Communications. Springer Berlin Heidelberg, 2010. 581-591.

[5] Chen, E. C. Bangladesh: Increasing Rural Farm-toMarket Capabilities through the Development of Infrastructure and Technologies.

[6] Vikal, S., Sharma, P., \& Singh, D. Bots: An Application Enhancement to Android Architecture.

[7] Hoog, A. (2011). Android forensics: investigation, analysis and mobile security for Google Android. Access Online via Elsevier.

[8] Ongtang, M., McLaughlin, S., Enck, W., \& McDaniel, P. (2012). Semantically rich application-centric security in Android. Security and Communication Networks, 5(6), 658-673.

[9] Jaeger, P. (2010, October). Smallholders: how to involve small-scale farmers in commercial horticulture. In 6th video seminar in the series High Value Agriculture in Southern and Eastern Africa.
[10] Lakhtaria, Kamaljit I. Technological Advancements and Applications in Mobile Ad-hoc Networks: Research Trends. IGI Publishing, 2012.

[11] IKSL: Kisan Sanchar, www.iksl.in

[12] Reuters Market Light (RML), www.reutersmarketlight.com/

[13] Oyeniyi, Omotayo, and Abiodun Abolaji Joachim. "Customer service in the retention of mobile phone users in Nigeria." African Journal of Business Management 2.2 (2008): 026-031.

[14] Singhal, M., Verma, K., \& Shukla, A. (2011, December). Krishi Ville-Android based solution for Indian agriculture. In Advanced Networks and Telecommunication Systems (ANTS), 2011 IEEE 5th International Conference on (pp. 1-5). IEEE.

[15] Glendenning, Claire J., and Pier Paolo Ficarelli. "The relevance of content in ICT initiatives in Indian agriculture." International Food Policy Research Institute Discussion Paper 1180 (2012): 1-40. 